\title{
Selection of R- and S-phase Colonies from Dimorphic Alcaligenes odorans var. viridans, and Their Isolation in Pure Culture
}

\author{
By B. BRZIN \\ Department of Microbiology, Medical Faculty, Ljubljana, Yugoslavia \\ (Received I8 December 1972; revised I4 February 1973)
}

\begin{abstract}
Alcaligenes odorans var. viridans was first described by Mitchell \& Clarke (1965), who observed colonial pleomorphism of the bacteria. They stated that neither type of colony bred true on subculture. Many strains were later isolated and studied by Brzin (197I), who found that fringe formation was occasionally observed in young colonies even though, in general, only older colonies, or, more often, only parts of them, were surrounded by a fringe. This early fringe formation was suspected to be due to the beginning of the R-phase dissociation of colonies of $A$. odorans var. viridans. Therefore selection of $\mathrm{R}$ - as well as $\mathrm{S}$-phase colonies and their isolation in pure culture was attempted simply by successive subculturing of the bacteria from typical parts of colonies. The two phases of $A$. odorans var. viridans were isolated in pure culture, tested for stability and their physiological and biochemical characteristics were compared.
\end{abstract}

\section{METHODS}

Strains of Alcaligenes odorans var. viridans were subcultured on $5 \%$ bovine blood agar every $48 \mathrm{~h}$. For the first $24 \mathrm{~h}$ they were incubated at $37^{\circ} \mathrm{C}$ and later at room temperature (about $22{ }^{\circ} \mathrm{C}$ ). The largest and most pronounced fringe was then picked at its extreme border, transferred to a fresh medium, and incubated for $24 \mathrm{~h}$ at $37^{\circ} \mathrm{C}$ and subsequently at room temperature for another $24 \mathrm{~h}$. The bacterial growth at the extreme border of the fringe around the new colonies was in this way serially subcultured, to give a pure culture of the R-type colony.

In a similar way, a pure culture of the S-type of Alcaligenes odorans var. viridans was obtained by successively subculturing the colonies which remained completely rounded and smooth even after prolonged cultivation at room temperature.

\section{RESULTS AND DISCUSSION}

In this simple way, the $\mathrm{R}$ - as well as the $\mathrm{S}$-variant of Alcaligenes odorans var. viridans became more and more pronounced until, finally, upon continued selection of typical Rand S-type growths, pure cultures of $\mathrm{R}$ - and S-colonies were isolated (Fig. I $a, b$ ).

In an effort to help the differentiation and isolation of the two phases of Alcaligenes odorans var. viridans, various media and other growth conditions were used, but with no significant effect.

Owing to its punctiform, greening growth and its ability to grow in salt broth, the S-colony type of Alcaligenes odorans var. viridans was even more similar to Enterococcus than was the original dimorphic culture; whereas the R-type strongly resembled Pseudomonas aeruginosa. 

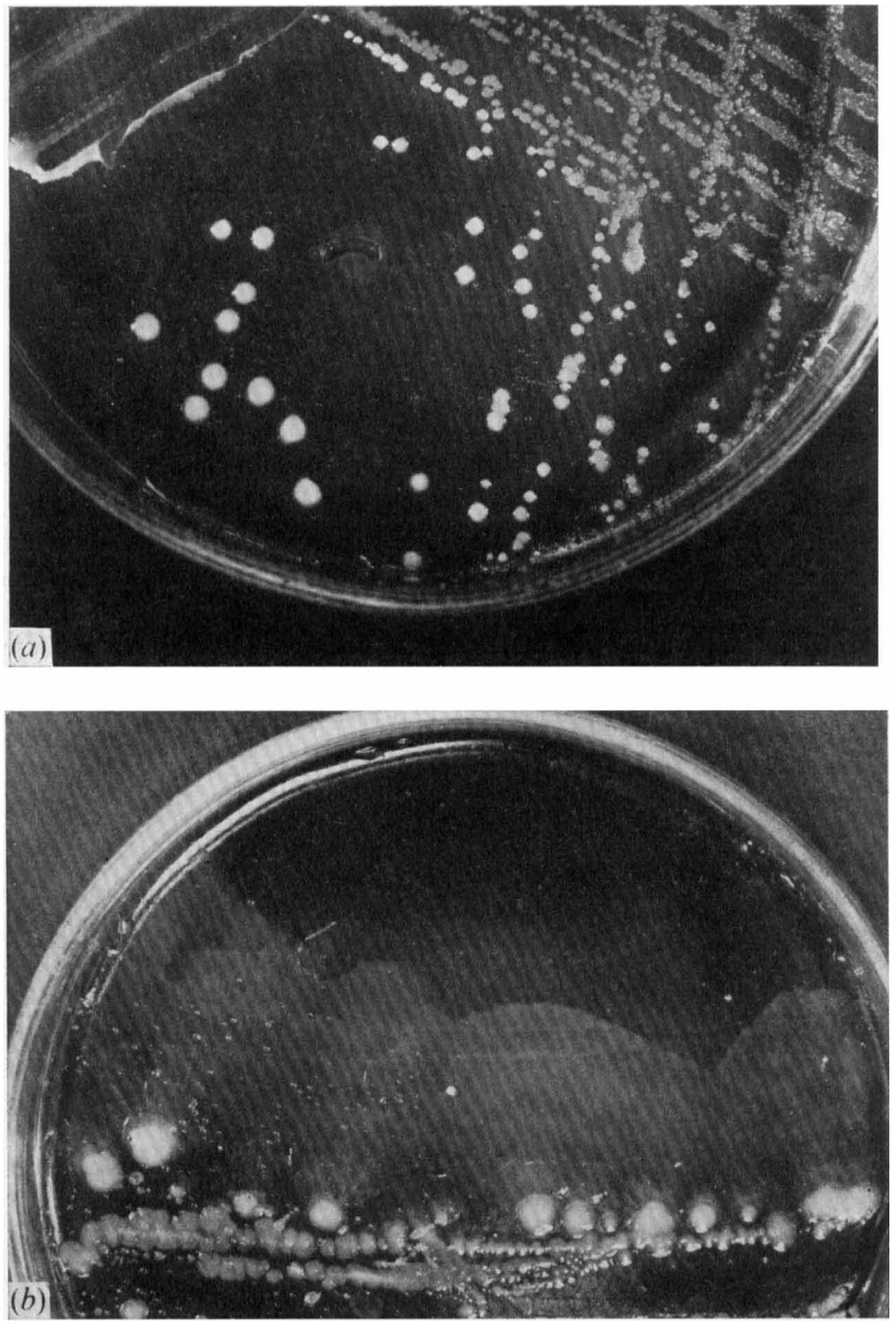

Fig. I (a) Smooth colonies of Alcaligenes odorans var. viridans. (b) Rough colonies of Alcaligenes odorans var. viridans.

During the first month after the isolation of cultures of the R- and S-type, the cultures were still unstable. When the bacterial growth to be transferred to fresh medium was picked at random, i.e. not at the extreme border of the fringe or from a completely rounded, smooth colony, the new culture soon tended to revert to a mixed one. After continued subcultivation the R-as well as the S-type of growth became stable. Cultures were influenced neither by varying physical factors (incubation temperature, degree of dryness of the medium) 
nor varying chemical factors (composition and $\mathrm{pH}$ of the medium, type and percentage of blood in the medium). The physiological and biochemical characteristics of the two colony types were found to be identical. In the antibiogramme test no difference was found between the reaction of either type to antibiotics or chemotherapeutics. Moreover, there was no difference between the two colony types in the characteristic features observed by Brzin (I97I), namely their ability to grow in salt broth $(6.5 \%)$, and the tendency of the bacteria to elongate in this medium.

Since with some bacteria the rough-smooth colony variation is a reflexion of bacterial size (Grula, I960a, $b$ ), the size of bacteria of each colony form was compared repeatedly and under various conditions. No significant difference in microscopic morphology was found between the R- and S-variant. In this case the rough-smooth colony variation did not seem to be a reflexion of bacteria size or of the presence or absence of a capsule. The observed change in colonial properties of these bacteria was probably due to spontaneous mutation involving the surface character. No cause-and-effect relationship was found between the chemical composition, $\mathrm{pH}$ or state of dryness of the media, and the readiness of these bacteria either to dissociate or to be isolated in a pure and stable culture of R- or S-type.

A change in type of growth in fluid media is sometimes coupled with aberrant bacterial morphology when culture conditions are not optimal. For example, the flocculent growth of Arthrobacter induced by too low a vitamin $B_{12}$ supply was found to be associated with abnormal bacterial morphology (Chaplin \& Lochhead, 1956). It is therefore possible that the absence of any significant difference in microscopic morphology between the R- and $\mathrm{S}$-variants was the reason why no great difference between the mode of growth in fluid media of each variant was observed. The R-variant grew more diffusely than the S-variant in nutrient broth, but showed only a weak tendency to creep along the inner side of the vessel and only occasionally formed a pellicle after prolonged incubation at room temperature.

Both colony-types of Alcaligenes odorans var. viridans are deposited in the National Collection of Industrial Bacteria (NCIB), held at the Ministry of Agriculture Fisheries and Food, Torry Research Station, I35 Abbey Road, Aberdeen, AB9 8DG; Scotland.

\section{REFERENCES}

BRzIN, B. (197I). Alcaligenes odorans varietas viridans. Zentralblatt für Bakteriologie, Parasitenkunde, Infektionskrankheiten und Hygiene (Abteilung I. Originale) 218, 56-60.

Chaplin, C. E. \& LochHead, A. G. (1956). Abnormal morphology of a bacterium resulting from a vitamin B-I 2 deficiency. Canadian Journal of Microbiology 2, 340-342.

Grula, E. A. (1960a). Cell division in a species of Erwinia. I. Initial observations relating to nutritional dependency. Journal of Bacteriology 80, 369-374.

Grula, E. A. $(\mathrm{I} 960 \mathrm{~b})$. Cell division in a species of Erwinia. II. Inhibition of division by D-amino acids. Journal of Bacteriology 8o, 375-385.

Mitchell, R. G. \& Clarke, S. K. R. (I965). An Alcaligenes species with distinctive properties isolated from human sources. Journal of General Microbiology 40, 343-348. 